\begin{tabular}{|c|c|c|}
\hline & $\begin{array}{l}\text { European Association for the } \\
\text { Development of Renewable Energies, Environment } \\
\text { and Power Quality (EA4EPQ) }\end{array}$ & $\begin{array}{l}\text { International Conference on Renewable Energies and Power Quality } \\
\text { (ICREPQ'12) } \\
\text { Santiago de Compostela (Spain), 28th to 30th March, } 2012\end{array}$ \\
\hline
\end{tabular}

\title{
Performance Improvement of a Heat Pump Assisted Solar Water Heating System
}

Ruchi Shukla ${ }^{a}$, K. Sumathy ${ }^{a}$, Samee Ullah Khan ${ }^{b}$

${ }^{a}$ Department of Mechanical Engineering

${ }^{\mathrm{b}}$ NDSU-CIIT Green Computing and Connections Laboratory

North Dakota State University Fargo, ND 58108-6050, (U.S.A)

Phone: 701-231-7139, fax: 701-231-8913, e-mail: Sumathy. Krishnan@ndsu.edu

\begin{abstract}
Details of a heat pump assisted solar water heating system, is briefly described. Refrigerants compromising of Fluorocarbons and Chlorofluorocarbons have been generally used as the working fluid. But due to its ozone depletion effect and high Global warming potential, they have been replaced by synthetic refrigerants such as R22, R134 etc. The heat pump utilizing such refrigerants has shown to attain efficiencies (COP) of the order only about 2 to 3 . In this paper an attempt has been made to find out the reasons for such low efficiencies and the possibility of using $\mathrm{CO}_{2}$ (R744) as the working fluid in heat pump assisted solar water heating systems. $\mathrm{CO}_{2}$ is one of the few natural refrigerants which is neither flammable and nor toxic. It is commonly obtainable and does not affect the global environment like other refrigerants. A few changes to be made in the experimental set up to improve the performance of the heat pump are discussed.
\end{abstract}

\section{Key words}

Heat Pump, R744, Evacuated tube collector, storage tank, Coefficient of performance

\section{Introduction}

In order to improve COP of the heat pump and displace the fossil energy resource, idea of combining the heat pump and solar energy in mutual beneficial ways has been proposed and developed by several researchers. Many theoretical and experimental studies have been reported in past 30 years. The solar collector is the heart of solar water heating system. During the last two decades, a number of researchers have worked on developing new and more efficient solar collector designs. Apart from the collector structure and absorptive coating, several works have been carried out to study the influence of different working fluids on collector performance. Solar water heating is a mature technology with several reliable designs; however, these designs cannot be effectively utilized in the region that experience freezing conditions. Among the working fluids, the most widely used and conveniently available is water. One of the main reasons is that working liquid freezes very rapidly in the cold locations within the connecting tubes of the solar water heating system. Furthermore, water has low air thermodynamic cycle efficiency. Other working fluids, such as silicon oil and ammonia also are commonly used. However, silicon has high viscosity and is difficult to handle, and ammonia is extremely toxic. A recent study reported $\mathrm{CO}_{2}$ (R-744) which is an environmentally safe working fluid can be used to energize ground source heat pump [16].

This paper is intended to analyze and discuss the thermodynamic aspects of $\mathrm{CO}_{2}$ as the working fluid for heat pump assisted solar water heating systems. To develop a reliable and efficient heat pump assisted solar heating system, a few modifications are suggested to enable them perform in solar adverse regions with low ambient temperature and low solar radiation intensity.

\section{System description}

The HPSWH consists of an evacuated solar collector as an evaporator, hot water storage tank with an immersed heat exchanger as condenser, thermostatic expansion valve and a small refrigeration compressor.

Figure 1 shows the schematic of a simple HP system. The refrigerant in the solar collector is evaporated by incident solar energy. The ambient air acts as an additional heat source or sink, depending on whether the refrigerant temperature is higher or lower than that of ambient. The vaporized refrigerant passes through the compressor, and finally the high temperature vapor is pumped into the condenser where it gets condensed. The energy rejected by the condenser contributes to load requirement through a refrigerant-to-water heat exchanger immersed in the hot water storage tank. 


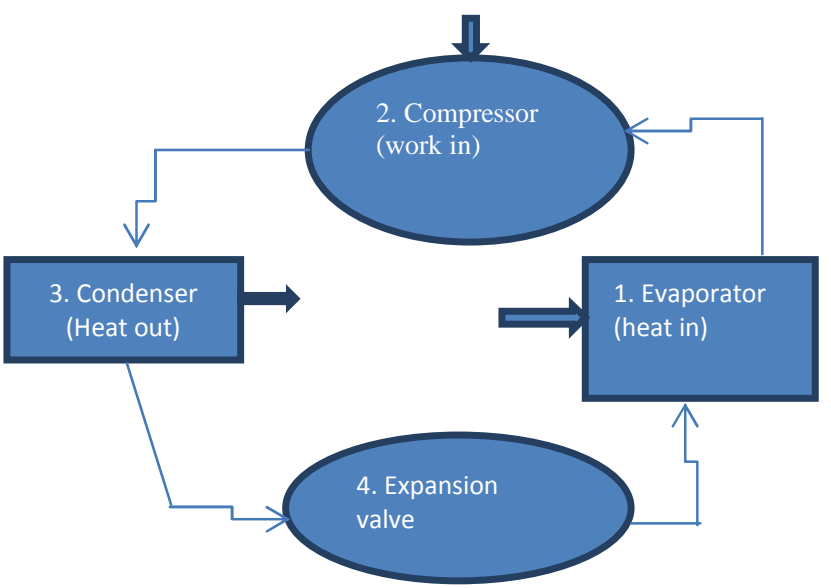

Fig.1. Heat pump components



Fig.2. Heat pump cycle on a p-h diagram [8]

The process undergone by the refrigerant during the first cycle of event can be represented by an idealized heat pump cycle as shown in Fig. 2. Stage 1-2 represents compressing the refrigerant at low pressure and temperature, to State 2 represents superheated vapor at condensing pressure. From here working fluid enters the condenser of tube-type cooling coil and leaves it as sub cooled liquid at the state 3 . The condensing of refrigerant is achieved by rejecting its heat to the cold water in the storage tank, and the warm water from the tank can be used for hot water application. The sub cooled refrigerant from the condenser is then pumped to the solar collector through an exhaust valve which is represented by state points 3-4. With the incident solar radiation, the refrigerant again boils off in the collector tube and the resultant superheated vapors leaves the collector at state 1 . Similar set of events keep occurring and the water in the storage tank gets heated to the required temperature.

Figure 3 shows the schematic of the commonly used air source HP assisted SWH system. The solar collector and heat pump are integrated together as a system that work in summer and winter modes. In summer, the thermal energy collected by the solar collector heats the refrigerant close to its supercritical state. The natural connective flow of the refrigerant will be induced by the: (a) heating process

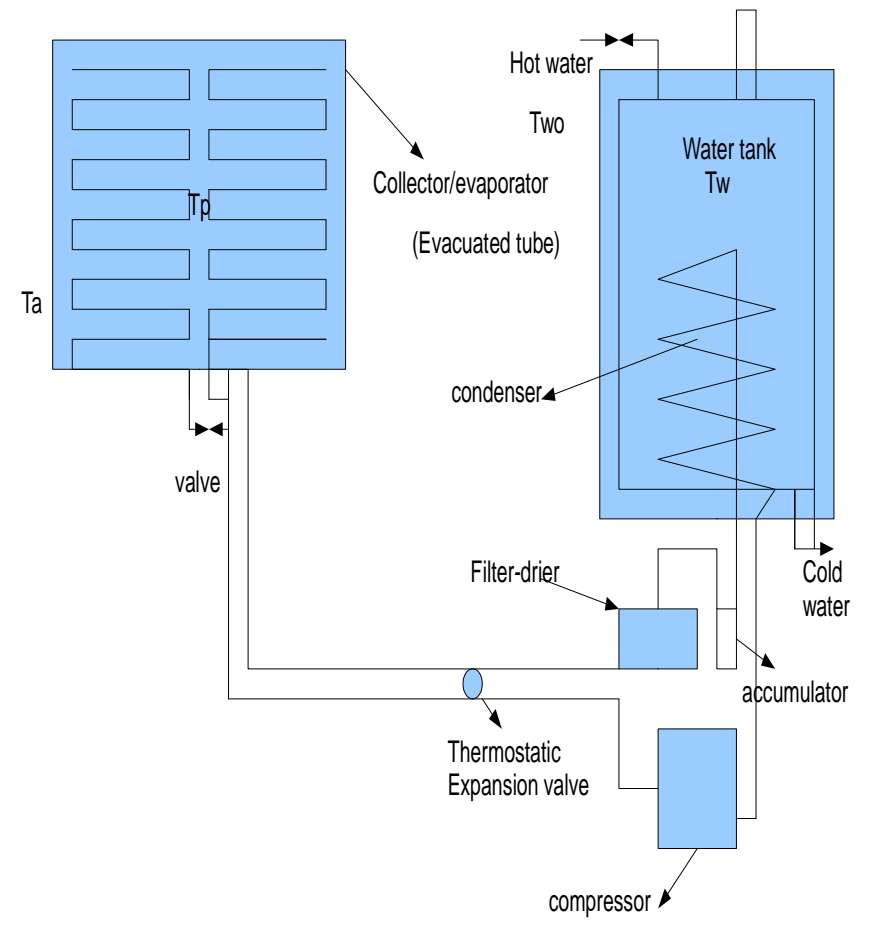

Fig.3. Schematic diagram of the HPSWH

via solar radiation and (b) cooling process as a result of heat exchanging with water in the water-tank.

In winter, when the surface temperature of the solar collector is considerably lower than the desired temperature, the compressed loop will be engaged. The vaporized refrigerant passes through the compressor, and finally the high temperature vapour is pumped into the condenser where it gets condensed. The energy rejected by the condenser contributes to load requirements (hot water applications) through a refrigerant-to water heat exchanger immersed in the hot water storage tank.

Air source heat pump uses outside temperature as a heat source or sink. One of the challenges of the air source heat pump is that its performance is very low, when ambient temperature is low. The working fluid would freeze very rapidly within the connecting tube of solar water heating system [10] [11]. Hence low ambient winter temperatures remain the key limiting factor in utilizing solar energy in such solar adverse regions. As the temperature falls, the heating output of low temperature optimized heat pumps declines, so do their efficiencies too. At temperature below $8^{\circ} \mathrm{C}$, air source heat pump can attain COP only about 2.2-2.8. Hence, research is being focused in improving the performance of heat pump when being operated in very low source temperature. 


\section{Modifications suggested to increase the efficiency of HPSWH system.}

To develop an efficient, cost effective and environmental friendly HPSWH that can function even when exposed to low ambient condition (less than $6^{\circ} \mathrm{C}$ ), the following design changes are suggested.

\section{1 $\mathrm{CO}_{2}$ as a working Fluid}

To overcome the "freezing problem", $\mathrm{CO}_{2}(\mathrm{R} 744)$ can be used as a working fluid which has significant advantages. $\mathrm{CO}_{2}$ is a non-freezing, non-volatile, non-flammable, noncorrosive, low cost, and non-toxic medium [3]. It does not need to be recovered or reclaimed when repairing or disposing of equipment but can be exhausted into the atmosphere with negligible impact. Moreover, utilizing $\mathrm{CO}_{2}$ as a working fluid will ensure higher heat transfer. Though $\mathrm{CO}_{2}$ has a minimal effect on the global warming potential, it is a natural refrigerant having no impact on the ozone depletion potential [Table 1]. Compared to other working fluid, the thermodynamic and transport properties of $\mathrm{CO}_{2}$ seem to be favorable in terms of heat transfer and pressure drop [11]. Its volumetric refrigeration capacity is 3-10 times higher than CFC, HCFC and HFC refrigerants. Carbon dioxide was among the first fluid used in refrigeration system, and its use remained significant until the introduction of CFC refrigerants in 1930's [3]. $\mathrm{CO}_{2}$ can be exhausted into atmosphere with negligible impact. Leaks in a $\mathrm{CO}_{2}$ system do not present the safety or environmental hazard of the other refrigerants. As well as being environmentally benign, carbon dioxide's thermophysical properties make it one of the most promising natural refrigerants for water heating and other applications requiring a high temperature increase. One property of $\mathrm{CO}_{2}$ which distinguishes it from other refrigerants is its low critical point i.e. $31.1^{\circ} \mathrm{C}$ at $73.7 \mathrm{bar}$ [Fig.4]. Carbon dioxide's low $\mathrm{T}_{\text {crit }}$ is one of the reason that its use was surpasses by other refrigerants [Table.1]. The transcritical cycle take advantage of $\mathrm{CO}_{2}$ 's low critical point by intentionally operating in the supercritical region during heat rejection [3]. The transcritical cycle allow $\mathrm{CO}_{2}$ to deliver higher temperature with improved COP. Another important distinction between $\mathrm{CO}_{2}$ and other refrigerants is the operating pressure. Both subcritical and transcritical heat pump systems using $\mathrm{CO}_{2}$ operate at much higher pressures than heat pump systems using conventional refrigerants. In a heat pump system, the compressor increases the refrigerant pressure in order to increase the heat rejection temperature. A heat pump using $\mathrm{CO}_{2}$ typically has a lower pressure ratio than an anlogous system using a synthetic refrigerant.

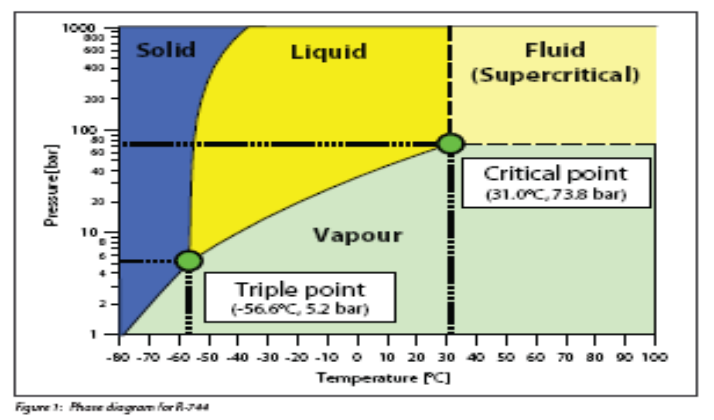

Fig.4. CO2 P-Chart [8]

Table1 Environmental benefits of $\mathrm{CO}_{2}$ : Comparison of Refrigerant properties [2]

\begin{tabular}{|c|c|c|c|c|}
\hline Refrigerant & R134a & R-404A & Ammonia & $\mathrm{CO}_{2}$ \\
\hline $\begin{array}{l}\text { Natural } \\
\text { Substance }\end{array}$ & No & No & Yes & Yes \\
\hline $\begin{array}{l}\text { ODP (ozone } \\
\text { depletion } \\
\text { potential) }\end{array}$ & 0 & 0 & 0 & 0 \\
\hline $\begin{array}{l}\text { GWP } \\
\text { (global } \\
\text { warming } \\
\text { potential) }\end{array}$ & 1300 & 3260 & none & 1 \\
\hline $\begin{array}{l}\text { Critical } \\
\text { point }\end{array}$ & $\begin{array}{l}101.1^{\circ} \\
4.07 \mathrm{Mpa}\end{array}$ & $\begin{array}{l}71.7^{\circ} \\
3.73 \mathrm{Mpa}\end{array}$ & $\begin{array}{l}132.2^{\circ} \\
11.3 \mathrm{Mpa}\end{array}$ & $\begin{array}{l}31.1^{\circ} \\
7.37 \\
\text { Mpa }\end{array}$ \\
\hline Triple Point & $\begin{array}{l}-103^{\circ} \\
.00040 \mathrm{Mpa}\end{array}$ & $\begin{array}{l}-100^{\circ} \\
.0028 \mathrm{Mpa}\end{array}$ & $\begin{array}{l}-77.8^{\circ} \\
.0060 \\
\mathrm{Mpa}\end{array}$ & $\begin{array}{l}-56.6^{\circ} \\
.518 \\
\text { Mpa }\end{array}$ \\
\hline $\begin{array}{l}\text { Flammable } \\
\text { or explosive }\end{array}$ & No & No & Yes & No \\
\hline Toxic & No & No & Yes & No \\
\hline
\end{tabular}

In the supercritical region certain properties of the fluid are similar to values of the vapor region while other properties are closer to values of the liquid region. For instance, the density of the supercritical fluid is closer to that of a liquid while the viscosity is more like that of a vapor. Unlike the liquid-vapor phase transition, there is no mixing of phases during transition from vapor to supercritical or liquid to supercritical [7]. Furthermore in the supercritical region and at the phase transitions, property variation will have no discontinuities. This is different from the property change that occurs at the liquid-vapor phase transition. Property change for supercritical $\mathrm{CO}_{2}$ is gradual an continuous except near the critical point where substantial changes in the thermophysical properties occur even for small changes in temperature and pressure. The region where such rapid change in properties takes place is known as the "pseudocritical region." The pseudo critical region has a pressure dependent temperature. $\mathrm{T}_{\mathrm{pc}}$ is defined as the temperature at which the specific heat capacity reaches maximum for given pressure. 


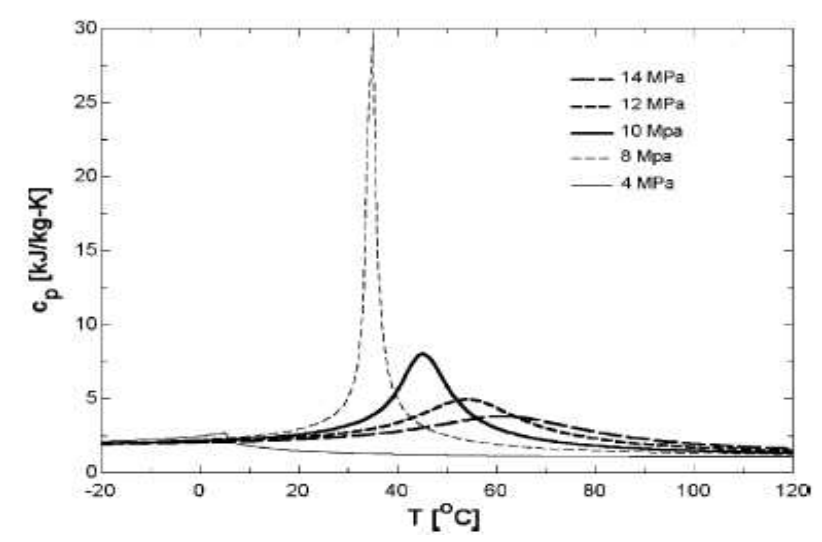

Fig.5. Variation of specific heat for $\mathrm{CO}_{2}$ [3]

Figure 5 shows the temperature-dependent variation in specific heat for different pressures. The figure shows as pressure increases the maximum specific heat occurs at greater temperature. In addition, as pressure increases beyond $8 \mathrm{MPa}$ then the peak specific heat value is lower [3], hence it will be beneficial to operate the system at critical region of $\mathrm{CO}_{2}$ to harness maximum energy.

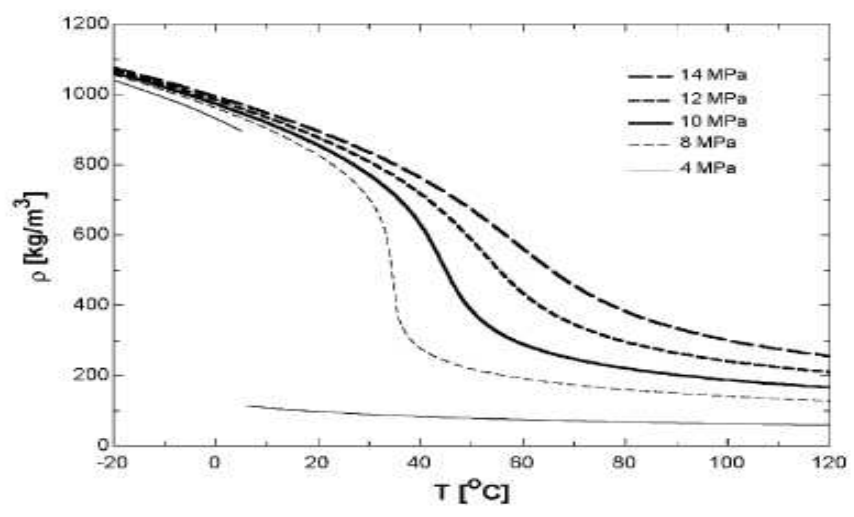

Fig.6. Density variation for $\mathrm{CO}_{2}$ through the $\mathrm{PC}$ region [3]

The density change of $\mathrm{CO}_{2}$ is shown in Fig.6. The density decreases rapidly through the $\mathrm{PC}$ region as temperature increases. The thermophysical properties of supercritical carbon dioxide are quite distinct from those of subcritical refrigerant.

\subsection{Evacuated Tube Solar Collector}

To further improve the HPSWH system's performance an evacuated solar collector can be redesigned to suit the specific system operation characteristics. Evacuated tube collectors can attain high temperatures very easily. They are best fit in the cold region. They can collect heat even if it's freezing outside. Because of their greater Incidence angle modifier, they keep absorbing solar energy throughout the day. The tubes are made from low emissivity borosilicate glass with a glass seal. The selective coating enables the use of the solar energy spectrum to generate heat. This produces greater thermal efficiency in bright sunshine but also gives high efficiency in diffuse sunlight conditions. The header is made up of copper which makes, it an outstanding heat transfer and is corrosion resistance.

As compared to flat plate collectors, evacuated tube solar collectors have got greatly selective coating and vacuum insulation of the absorber element which allows them to have high heat extraction efficiency. The convection and conduction heat loss to outside be greatly reduced because of the vacuum that surrounds the outside of the tube. Therefore they have more efficiency compared to flat plate solar collector, mainly in colder regions. They are highly used in residential applications, which require higher temperature because of its lower heat loss. Heat cannot loss across a vacuum, which creates an effective isolation mechanism to have the heat inside the tubes.

\subsection{Stratified storage tank}

Along with the solar collector, the storage tank plays a key component in dictating the systems performance. In order to improve the system performance of the conventional system designs, a partitioned hot water storage tank is introduced as one of the modification. An important aspect of storage tank is stratification, which depends on the inlet design of the storage tank and other factors such as heat conduction within the tank as well as side losses, inlet jet mixing, plume entrainment. As for inlet mixing and plume entrainment is concerned, an inlet distributor manifold and variable design will positively improve the temperature stratification profile in the storage tank. Plume entrainment often occurs in low-flow systems at midafternoon when the availability of solar energy decreases. As a result, water entering the tank from top will be cooler than the water in the upper part of the tank producing a downward flowing plume. This can in turn reduce the temperature in the upper significantly. One of the simple methods is to provide a light flexible hose to be connected to the tank inlet. Due to buoyancy forces, the outlet of the hose would automatically float to the correct depth. Heat loss through the wall and fluid is unavoidable, but its influence can be reduced by keeping stratification and by providing good insulation. The overall system performance is significantly affected by the storage temperature distribution; therefore stratification is needed with in the storage tank in order to provide accurate solar heating.

To maintain stratification, a simple new baffle inlet technique was introduced by Davis and Bartera in 1975 [10]. Two solid baffle plates are placed near the inlet of the tank. The flow from the solar collector and from the load enters the tank through two inlet ports at mid-height and impinges on the plates where it gets diverted vertically up or down depending on the difference between the inlet and local tank fluid temperature. The collector return flow in-between the plates can locate at a position with the temperature close to its own. To ensure 
the reliability of the system design, a proper size of the storage tank is also essential.

\section{Conclusion}

The above analysis shows that considerable modifications can be made in the experimental set up to improve its efficiency. Identifying the key operational parameters to achieve high thermal performance of the solar heat pump assisted solar water heating system. The assumption made in the theory should suit the practical condition to have a clear picture of what is happening in the solar water heater. This work, both experimental and theoretical is in progress.

\section{Acknowledgement}

This research was in part supported by a grant from the Pakistan-US Science and Technology Cooperation Program, US Department of State (jointly administered by the National Academics and Higher Education Commission of Pakistan).

\section{References}

[1] U.S DOE.2009.Heat pumps systems. Retrieved November 29, 2009, from U.S Department of Energy:

www.energysavers.gov/your_home/space_heating_cooling/inde X.cfm/mytopic $=12160$.

[2] Vestergaard, N.P, and Robinson, M.2003.CO2 in

refrigeration Applications. Retrieved October 30, 2009, from Air

Conditioning Heating Refrigeration News:

News:www.achrnews.com/Articles/Feature_Article/cc753504dd c5a010VgnVCM100000f932a8c0

[3] Kim, M.H, Pettersen, J, and Bullard, C.W.2004. Fundamental process and system design issues in $\mathrm{CO} 2$ vapor compression systems. Progress in Energy and Combustion Science. Vol 30 pp 119-174.USA.

[4] Lorentzen, G, and Pettersen, J. 1992.New possibilities for non-CFC refrigeration. Proceedings of the IIR International
Symposium on Refrigeration, Energy \& Environment. Trondheim, Norway.

[5] Thermophysical properties of Fluid systems. 2008. U.S.

Secretary of Commerce. Retrieved May 14, 2010, from National Institute of Standards and Technology: http://webbook.nist.giv/chemistry/fluid

[6] Aartun I. 2002. Carbon Dioxide pressure enthalpy diagram. Center of Applied Thermodynamic Stidies, University of Idaho.

[7] Pacific Northwest National Laboratory. 2003. About Supercritical Fluids. Retrieved May, 2007, from Pacific Northwest National Laboratory:

http://www.pnl.gov/supercritical fluid/about.stm

[8] Danfoss. 2008. Transcritical refrigeration system with carbon dioxide(CO2). Danfoss. Denmark.

[9] http://en.wikipedia.org/wiki/Solar_thermal_collector

[10] Li Zhongfu and K. Sumathy, "Experimental studies on a solar powered air conditioning system with partitioned hot water storage tank", Solar Energy, Vol.71,pp.285-297,2001.

[11] Zhang, X. R., Yamaguchi, H., Fujima, K., Enomoto, M., and Sawada, N., "Theoretical analysis of a thermodynamic cycle for power and heat production using supercritical carbon dioxide", Energy, Vol.32 (4), pp.591-599, 2007.

[12] Kuang, Y.H., Sumathy, K., and Wang, R.Z.,"Study on a direct -expansion solar assisted heat pump water heating system,"International J. of Energy Research, Vol.27, pp.531548, 2003.

[13] http://en.wikipedia.org/wiki/Solar water heating

[14] http://www.preheat.org/fileadmin/preheat/documents/interso lar/Simon_Furbo_Heat_storage_for_solar_heating_systems.pdf

[15] Brian T.Austin and K.Sumathy. (2011) "Parametric study on the performance of a direct expansion geothermal heat pump using carbon-dioxide," Applied Thermal Engineering, 31:3774-3782. 